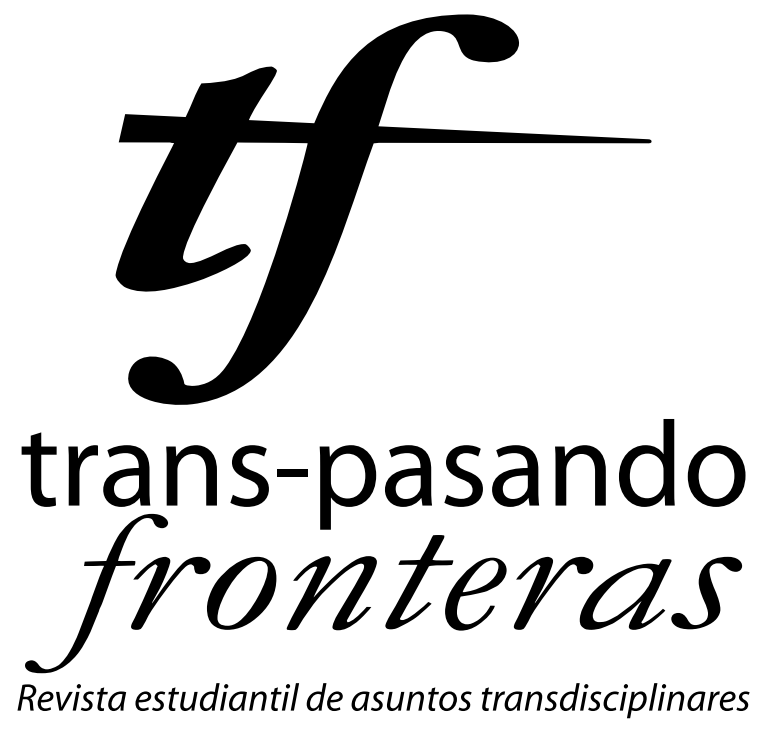

Una publicación de

Facultad de Derecho y Ciencias Sociales

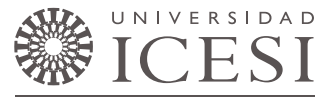




\title{
Algunos apuntes sobre los problemas de tierras, minería y agro en Colombia
}

\author{
Entrevista a Jorge Robledo \\ Senador de la República por el Polo Democrático Alternativo
}

\author{
Por Carlos Liévano \\ Estudiante de Ciencia Política con concentración en Relaciones \\ Internacionales y representante estudiantil al Consejo académico \\ (carlos.lievano10@gmail.com)
}

La entrevista fue realizada el día viernes 17 de Agosto de 2012 en la Universidad Icesi, aprovechando que el Senador fue invitado a realizar una ponencia en un evento sobre el Tratado de Libre Comercio (TLC) y la Salud, en la Universidad Javeriana de Cali.

Se escogió hablar de tierras y minería porque son temas de la Comisión Quinta Constitucional Permanente del Senado, de la cual el Senador Robledo es miembro. Además, sabemos de su experiencia en este tipo de temas por debates anteriores que han logrado exhibir casos como el de Agro Ingreso Seguro, Carimagua y los relacionados al caso de minería en
Cerromatoso y Marmato. Asimismo, es interesante conocer una opinión diferente a la emitida por la Unidad Nacional del presidente Juan Manuel Santos en el congreso, como la de un integrante del único partido de oposición en Colombia, el Polo Democrático Alternativo (PDA).

Carlos Liévano (CL): Iniciemos la entrevista con el siguiente enunciado:

"Antes de la revolución francesa, los nobles, que representaban el 1,5\% de la población, eran dueños del 35\% de la tierra cultivable. En Colombia no hay nobleza, pero la situación es peor que la del antiguo régimen. Tenemos cerca de 16.000 


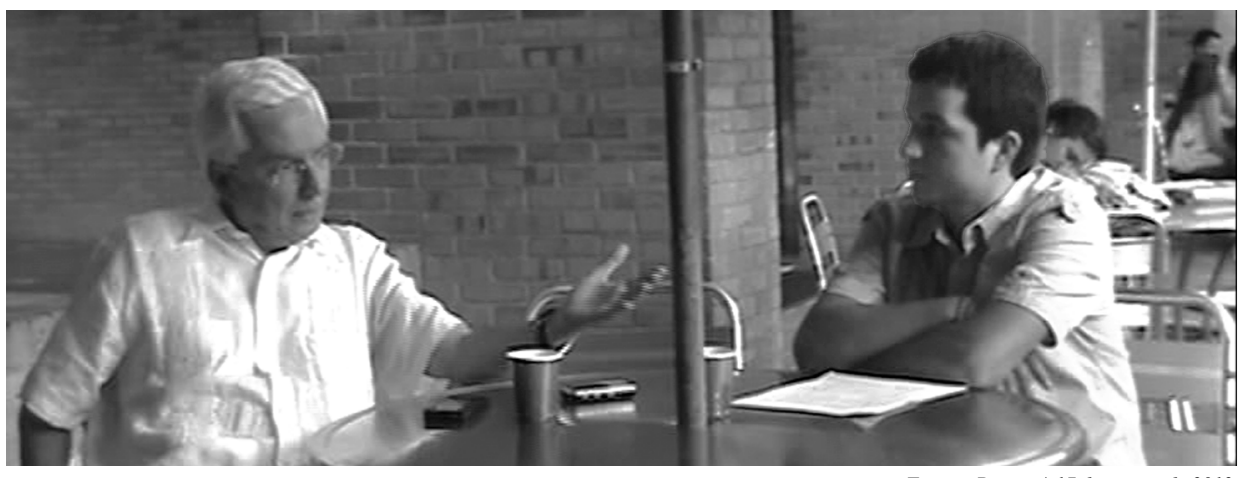

Fuente: Propia | 17 de agosto de 2012.

"es evidente que quienes gobiernan a Colombia no son capaces de resolver los problemas del país, ellos dicen y dicen cosas pero el país está metido en un callejón sin salida, porque al final les va bien a ellos pero al país no"

finqueros, que representan el $0,4 \%$ de los propietarios y que controlan el $62 \%$ de la tierra cultivable". ${ }^{1}$

Teniendo en cuenta lo anterior, ¿Cuál es el estado actual de la concentración de la tierra en Colombia?

Jorge Robledo (JR): Colombia tiene un índice de Gini, que es una manera de medir concentración de la tierra, de 0.87. Eso significa que si toda la tierra fuera de una persona, el Gini sería 1.0,en este sentido, un Gini de 0.87 es, o el país con más

1 VILLEGAS GARCÍA, Mauricio (2010). "Tierra y Bicentenario". En: El Espectador, agosto 27 de 2010 . concentración de la tierra en el mundo, o uno de los países de mayor dispersión de la tierra en el mundo. Esto es un hecho estadístico que tiene consecuencias sociales complicadas.

En relación a los niveles de pobreza, Colombia es el tercer país con mayor desigualdad del mundo en contraste entre la extrema riqueza y la extrema pobreza. Entonces, nuestra situación es lamentable.

CL: ¿Cuál es la posición asumida por usted, y por la bancada del Polo Democrático Alternativo, frente a la ley que formuló el gobierno el año pasado, la Ley de restitución de tierras? 
JR: Nosotros somos partidarios de la restitución de la tierra en Colombia pues es obvio que si a una persona le han robado la tierra mediante la violencia, lo elemental es que el Estado haga esfuerzos por devolvérsela. Sin embargo, cuando llegó la hora de votar, después de haberle escrito dos cartas al presidente Santos diciéndole que la Ley que estaba tramitando era mediocre, que era cicatera, el gobierno no nos hizo caso.

Entonces, en la última votación, decidimos presentar nuestro propio Proyecto de Ley como una manera de decir “estamos de acuerdo con la restitución de tierras pero ese proyecto del gobierno no es un buen proyecto". Pero sin duda somos partidarios de la restitución. Lo que pasa es que el proyecto del gobierno fue un proyecto que quedó con serias dificultades.

CL: Gerardo Vega, el director de la Fundación Forjando Futuros dice:

"Luego de un año de sancionada la Ley de restitución de tierras, hay lentitud y retraso del Estado para hacer viable la restitución de tierras. Hay que darle un tizonazo a la norma porque si seguimos así, nos podemos quedar con una muy buena Ley pero sin aplicarla".

2 Editorial de El Tiempo (2012). "Hay lentitud del Estado en hacer viable la restitución de tierras, de la
¿En qué estado se encuentra el proceso de restitución de tierras en este momento?

JR: Digamos que cuando empezó este proceso, el gobierno nacional anuncio que iba a restituir 300.000 mil hectáreas a 130.000 colombianos. Antes de aprobada la Ley, se habló de un plan de choque para hacer esto; ahora, el resultado de todo esto ha sido un fracaso absoluto pues no se ha restituido ni una sola hectárea. En enero entró en vigencia la Ley 1448 sin embargo, hasta el momento no se han visto resultados, lo cual no es extraño, pues dicha Ley está recién aprobada. Pero sí enfatizo, que lo que iban a hacer desde el Ministerio de Agricultura y Desarrollo Rural por vía administrativa no lo hicieron.

Ahora, ¿cuál es la parte más grave que resulta de todo esto?. Es que el gobierno en Enero, a través del ministro Juan Camilo Restrepo dijo que aspiraban realizar 2.400 restituciones este año y hacer unas 8.000 y tantas el año entrante, lo que suman un total de 10.400 restituciones, y resulta que el gobierno prometió que iba hacer más de 130.000. En conclusión, es evidente que no van a cumplir. Pero ahora, cuando le hago el reclamo al gobierno, se ponen bravos y dicen que ellos no se comprometieron con

sección de Política”. En: El Tiempo, agosto 15 de 2012. 
ninguna cifra y que lo que sí prometieron, en su Plan Nacional de Desarrollo, es que esa cifra era el número de restituciones a alcanzar para el 7 de agosto de 2014. Ahora, esto ya es un hecho grave, pero hubo una cosa que me ha parecido mas perturbadora, y es que el gobierno duró más de un año diciendo mentiras sobre la restitución, presentando otras políticas del Estado que tienen que ver con tierras pero que no son restitución de tierras; titulaciones de baldíos a colonos, afrodescendientes, resguardos indígenas, etc.

En mis debates pudimos develar esa patraña, y hoy, ya el gobierno ha tenido que reconocerlo. Lo dijo en estos días el Presidente Santos, que van cero hectáreas restituidas, al igual que el doctor Alejandro reyes (asesor de agricultura) hace pocos días en una entrevista para La Silla Vacía, tuvo que reconocer que el Presidente de la República había manipulado las cifras al presentar como restituciones otras medidas de tierras. O sea, que el balance es bastante malo.

CL: Con todas estas cifras presentadas y el incumplimiento que ha tenido el gobierno en la restitución de tierras, este dice que se está haciendo una "revolución agraria", una verdadera reforma que el país adeudaba hace mucho tiempo. ¿Cuál debe ser esa verdadera reforma agraria que necesita el país en este momento?

JR: Digamos esto, a la gente no hay que juzgarla por lo que dice de sí misma sino por lo que hace. Entonces, ya hemos visto que las cifras de restitución son horribles, pero el Presidente Santos ha salido por Colombia a hablar de una "revolución agraria", a decir que él era el Presidente de los campesinos, abusando en ese momento de la falta de información de la gente. Hoy, cuando ya he logrado, en parte, que la información se conozca mejor no han vuelto a decir eso, porque entre otras cosas, si lo siguen diciendo se los van a terminar llevando para Sábados Felices, ${ }^{3}$ porque es evidente que lo que dicen no corresponde con los hechos.

Luego, la reforma agraria es un problema que tiene que ver con la tierra, pues no puede haber agro si no hay tierra y en Colombia hay un problema de acceso a la tierra muy grave. Este gobierno además, hizo una reforma en el Plan Nacional de desarrollo para concentrar la tierra todavía más. Está en la política de extranjerizar la propiedad rural en Colombia entregándosela a inversionista extranjeros,

3 Programa de televisión colombiana producido por el Canal Caracol, donde se presentan comediantes y humoristas nacionales. 
en ese sentido la política de Juan Manuel Santos es horrible, pero hay una cosa que, si se quiere, la hace más horrible, y es que sin tierra no hay agro, pero con solo tierra tampoco. Yo puedo tener tierra, pero si la política del libre comercio llena al país de importaciones agrícolas, la prosperidad agraria no es posible.

La concentración de la tierra en Colombia tiene dos orígenes, uno relacionado con la violencia, el cual es muy mencionado. Pero hay otra manera de concentrar la tierra en Colombia, es cuando las políticas agrarias arruinan a los productores, campesinos o empresarios y la tierra se concentra, que es en buena medida lo que está sucediendo en Colombia. Entonces atender el problema de la tierra y del agro tiene que empezar por una política agraria que garantice que Colombia va a promover la autosuficiencia alimentaria y que va a dejar de aplaudir como aplaude este gobierno, que Colombia este importando más de 10 millones de toneladas de productos del campo.

CL: Otro de los temas que queremos tocar es el tema de la minería, que sabemos pues, es la "locomotora" de Juan Manuel Santos, de la que tanto ha hablado desde principios de gobierno, que se encuentra plasmada en el Plan Nacional de Desarrollo (2010-2014).

"En 2002 el área titulada para explora-
ción y explotación minera era de $0,98 \%$
del territorio del país y en 2009 era de
8,4 millones. Al cierre del Gobierno
Uribe quedaron 40 millones de hectáreas
adicionales en estudio por Ingeominas
para definir si entregarlas o no en con-
cesión. Estamos hablando del $36 \%$ de la
superficie del país, el dilema es si vale o
no la pena entregar el país a la minería."

¿Qué considera el Plan Nacional de Desarrollo, que se presentó apenas inició el gobierno de Santos, en cuanto a la minería?

JR: El gobierno ha hablado como de cinco locomotoras, si uno mira las otras cuatro, donde está vivienda, educación y otras cosas, no hay nada. Es más, es lo mismo que venía haciendo el gobierno anterior. Yo un día le pregunte a un ministro y se río, le dije "bueno ministro explíqueme porque una cosa que el sábado 6 de Agosto no era nada, y el 7 de Agosto esa misma cosa se volvió locomotora".

La verdad es que si uno mira las famosas locomotoras, exceptuando la minería, todas son es carritos de balineras, ahí no

4 RUIZ, Juan Pablo. (2010). "Minería y Plan de Desarrollo". En: El Espectador, diciembre 21 de 2010 . 
hay nada que valga la pena. Ahora la locomotora minera es locomotora o aplanadora porque los daños que está causando son inmensos. Es cierto que ahí se está moviendo un montón de plata, pero hay ciertas cosas que hay que mirar sobre la minería para entender este fenómeno. Los impactos ambientales mineros suelen ser muy graves, las relaciones laborales que se imponen en el sector y en el mundo de las trasnacionales no son buenas, las regalías y los impuestos que pagan son escasos, o sea que allí hay unas deficiencias graves.

Pero probablemente lo más grave que tiene la locomotora minera de Santos es que no es una política minera calculada para sumarle al agro y a la industria, para agregarle al desarrollo agrario e industrial, sino para reemplazarlos. Es decir, Colombia tiene un fenómeno muy grave de revaluación de la moneda, enfermedad holandesa, que en parte la provocan las inversiones en minería, y es obvio que la minería sola no es capaz de sacar un país adelante, yo diría que la parte más perniciosa de la minería, además de las cosas que más se mencionan, ambientales, etc. es esta concepción que es profundamente retardataria, porque se está acabando el agro y la industria y sin agro e industria no hay como sacar el país adelante.
CL: Senador, ahora hablábamos de un problema en la titulación de tierras, también evidenciamos un problema en lo que se llaman "títulos", que exponencialmente han venido aumentando en los últimos años, y pues sabemos que el origen de estas solicitudes principalmente la hacen trasnacionales de la minería, ¿cuál es el problema real que tiene esta adjudicación de tantos títulos mineros y a estas multinacionales?

JR: Esto ha generado otro problema de minería que es muy grave, y es que las transnacionales se cogieron todos los títulos, inclusive de minas o de mineros que las estaban explotando hace 100 y 200 años; por ejemplo aquí en el valle comunidades afrodescendientes o indígenas.

Entonces se ha creado un problema extremadamente grave porque hay centenares de miles de mineros en Colombia, que llevan toda la vida haciendo minería, y que ahora resulta que los están metiendo a la cárcel porque no tienen títulos mineros porque los títulos se los dieron a las transnacionales. Esto es, Santos prefiriendo al capital extranjero sobre los nativos, además tiene una política de persecución contra la pequeña y mediana minería, que es muy grave, montada sobre una mentira, que es decir que es que todos son de 
las FARC, cuando por supuesto que eso es un despropósito, no hay sector de la economía en Colombia que no tenga algún tipo de actividad ilegal; pero decir que todos los pequeños y medianos mineros son criminales, es una desproporción, y que tiene que ver con favorecer los intereses del capital transnacional que se ha apropiado pues de prácticamente casi todo el territorio del país.

CL: Ahora, consideremos el siguiente horizonte de posibilidades:

"Pese a las ambiciosas pretensiones del Ejecutivo, una auditoría realizada por la Contraloría General de la República (CGR) deja en evidencia el desorden institucional que existe en este sector y cómo se están generando pérdidas millonarias en los recursos que debe recibir el Estado por cuenta de las regalías".

¿Qué opinión le merece la forma como se está abordando la extracción minera en Colombia y lo que se está dejando de tributar por este concepto?

JR: En el mundo minero colombiano hay una especie de caos, que tiene que

5 Alianza informativa "Noticias caracol" y "El Espectador" (2012). "Minería, una Locomotora fuera de rieles". En: El Espectador, febrero 12 de 2012. ver con muchas cosas y que se expresa de mil maneras. Niveles de corrupción estatal miedosos. En estos días, por ejemplo, hemos estado estudiando el contrato de Cerromatoso y es un contrato leonino, ilegal que seguro que tiene un origen en la corrupción, lo que encuentra son cosas horribles.

La Contraloría General de la República por ejemplo, ha dicho que las cifras que dan las grandes mineras de los macro proyectos mineros, cifras que tienen que ver con impuestos y con regalías, que el gobierno no tiene capacidad para auditarlas, que se les cree por fe. A mí me parece muy respetuoso que en asuntos de religión la gente crea por fe, pero en negocios creer por fe es un absurdo. Es una cosa caótica realmente lo que hoy se tiene en este mundo de la minería ya que ha causado muchos daños de diversos tipos al país.

CL: A parte de lo que mencionaba del problema de las regalías que deja de recibir el país por las exenciones tributarias que se les hace a las multinacionales, también hay un problema en la revisión y fiscalización por el concepto de títulos mineros y las regalías que estas dejan. ¿Cómo se está viendo el problema de tributación y falta de vigilancia?

JR: Es un poco lo que mencionaba, 
hay una especie de caos y en medio de un mar de corrupción y de procedimientos arbitrarios. Por ejemplo, normas calculadas para defraudar a la gente. Una cosa que debería conceder legalidad, que son los hechos y la práctica, eso se desconoce. Entonces hay casos, aquí en la zona de salvajina, comunidades negras que explotan una mina hace 200 años y de repente aparece un $\mathrm{Mr}$ y dice esa mina es mía porque yo tengo el titulo. Entonces como es posible que les titulen cuando de hecho hay una ocupación que es centenaria, y así como esos se pueden contar mil historias.

A donde uno se asome es horrible, en petróleo hay cosas que son espantosas, en todas las formas de minería, hay un caos en medio de la corrupción y el desorden.

CL: Teniendo este panorama sobre el problema de la minería en el país, ¿hacia qué modelo de minería o de extracción minera debe apostarle el país para que verdaderamente contribuya a su desarrollo?

JR: Yo soy de los que creo que en Colombia, el estado debe reconocer que hay por lo menos tres formas de minería, eso no está reconocido en la legislación con claridad y ese es parte del desorden, hay gran minería que son en general de trasnacionales, hay en el otro extremo minería artesanal, de bare- queros, gente que con una batea se rebusca la vida, y la mitad hay un grupo importante de pequeños y medianos empresarios mineros, muchos de ellos utilizan retroexcavadoras y algunas maquinas, esos son digamos los tres grandes sectores. El gobierno ha desatado una política de todas la gabelas a las trasnacionales, a las que le entregan el país como si estuviéramos en los días de la corona española, y hacia el resto de la minería una política punitiva, de perseguirlos, de meterlos a la cárcel, de maltratarlos, acosarlos, tratarlos de guerrilleros y paramilitares, eso es un absurdo.

Yo creo que en Colombia hay que desarrollar normas que permitan la existencia de esos tres tipos de minería, y cada una de ellas cumpliendo bien con todas las cosas, o sea, cuidando el medio ambiente, relaciones laborales como deben ser, pagando los impuestos, las regalías que hay que pagar, hacer una cosa civilizada que es lo que no existe. Pero eso por supuesto no es posible porque la política del Gobierno Nacional es aprovecharse un poco de la confusión para que todo se quede en manos de las trasnacionales violando normas y haciendo las cosas como no deben ser, atropellando, sacrificando el medio ambiente y las relaciones laborales al tiempo que con la policía y el ejército se persigue a los otros, una política que es completamente absurda, pero por sobre todo 
Colombia necesita entender, y eso no lo va hacer nunca, que la minería puede jugar un papel, yo he dicho "minería sí, pero no así".

También he insistido en otra cosa, no para reemplazar el agro y la industria, no para generar revaluación y enfermedad holandesa, no para destruir el resto del aparato productivo nacional, porque un país como Colombia si se especializa en minería le podrá ir bien a unas cuantas trasnacionales y unos cuantos criollos vinculados a esos negocios de las trasnacionales, pero el país en su conjunto se acaba, es que la minería uno de los líos que tiene y sobre todo la gran minería, es que produce muy poco empleo, es una actividad intensiva en capital, de grandes maquinas pero empleo muy poco; entonces si queremos que en Colombia haya empleo que tiene que ser propósito de una política económica sana, de cualquier tipo, por supuesto que eso esta es en la industria y en el agro, y la minería como la están utilizando es parte del martillo contra esos sectores.

CL: Senador Robledo me interesa saber qué solución le está dando Colombia a los cafeteros que se están organizando debido a que el precio internacional no está a niveles de solventar el precio na- cional y se están quedando con el café y con deudas y es un sector que ha sido por tradición uno de los más fuertes.

JR: El lunes anterior al día de la grabación de esto, hicimos una movilización cafetera muy grande en Manizales, hubo cerca de 20.000 cafeteros de 10 departamentos del país. ¿Qué conclusión pudimos sacar de esa gran movilización? Primero que hay una crisis profunda, el precio interno es muy malo, la cosecha ha caído verticalmente. Colombia alcanzo a producir cerca de 17 millones de sacos y estamos en menos de 8 millones, hay un problema de pobreza en las zonas cafeteras barbará. Zonas cafeteras que siempre han sido estructuralmente débiles, el 95\% de los cafetales tiene menos de 5 hectáreas, los cafeteros acomodados son poquísimos, hay un problema muy complicado.

Esa movilización tenía que ver con exigirle al gobierno nacional cambio de políticas y respaldo cierto a la caficultura, porque si el Estado no respalda a el agro, pues no puede desarrollarse, eso es algo que esta sabido en todas partes, y además del respaldo al agro con cosas que tienen que ver con un buen precio interno, créditos, asistencia técnica, control a los precios de los insumos; se hizo énfasis en un asunto que es clave, es que Santos anda con el 
cuento de aumentarle los impuestos a los cafeteros, se hizo un rechazo de plano a eso, porque es un absurdo que a un sector que está bien quebrado además le quieran aumentar los impuestos.

Ahí hay un problema que es muy complicado. Yo creo que la crisis del café es la expresión del fracaso de todas estas políticas del libre comercio, se supone que la felicidad consiste en exportar, los cafeteros han sido exportadores toda la vida y están más arruinados que nunca, es más, ya ni siquiera son capaces de producir el café del consumo nacional. Hoy Colombia está importando el 70\% del café que nos tomamos (el 70\% de este café, es café extranjero). La crisis del café es una crisis de proporciones inmensas, es evidente que quienes gobiernan a Colombia no son capaces de resolver los problemas del país, ellos dicen y dicen cosas pero el país está metido en un callejón sin salida, porque al final les va bien a ellos pero al país no le va bien.

CL: Ya para finalizar, voy a hacer una pregunta a parte de las tierras y la minería. Estamos terminando este año 2012 y ya se empiezan a ver algunas campañas, algunas caras presidenciables para 2014. En el actual gobierno de Juan
Manuel Santos, ha surgido el puro centro democrático, y otros movimientos como progresistas y marcha patriótica, el Polo democrático alternativo es otra opción. ¿Cómo se ve el panorama de la izquierda en Colombia para afrontar unas elecciones presidenciales para 2014 ?

JR: El Polo va a jugar un papel muy activo en las elecciones de 2014, y estamos mirando y seguramente el Polo va a tener a alguien aspirando a una candidatura presidencial. Pero también lo que esta viéndose con cada vez más claridad es que será una candidatura presidencial que vaya más allá del Polo, Con el Polo sí, pero que vaya más allá hacia otros sectores de izquierda y de incluso de gente que no se sienta de izquierda pero que esté de acuerdo con impulsar ciertas transformaciones democráticas que necesita Colombia, una cosa que vaya desde indígenas, campesinos, obreros, clases medias, empresarios, y dentro de ese proyecto pues habrá que escoger el candidato o la candidata presidencial que sea del caso. Eso es lo que digamos hasta ahora tenemos visto.

CL: Pasa algo para las próximas elecciones presidenciales muy interesante, y es que en las últimas elecciones el ex presidente Uribe le endosó todo su capital polí- 
tico al candidato presidencial Juan Manuel Santos, en las próximas elecciones eso no va a pasar, Santos va a jugar solo por primera vez, sin el respaldo político del ex presidente Uribe, el uribismo seguramente tendrá su propio candidato del puro centro democrático, que de centro seguro no tiene mucho, y el presidente Juan Manuel Santos seguramente apostara a una reelección presidencial, y hay el espacio para que se dé una tercera posibilidad ya que estas dos fuerzas van a competir en un mismo espectro ideológico, seguramente van a quitarse votos entre ellos y se dé la posibilidad que aparezca una nueva opción.

Esta semana en un programa en cable noticias vi una charla entre usted y Antonio Navarro Wolf, donde él de alguna forma le insinuaba a usted que se debía buscar la posibilidad de hacer un acuerdo político amplio para buscar una candidatura común, ¿El Polo le apuesta a esa posibilidad?

JR: Es claro que desde las fuerzas retardatarias del país va haber dos candidaturas, y lo obvio es que del otro lado hagamos el esfuerzo por montar otra candidatura, ahí debe estar el Polo, y el Polo aspira a que sea alguien de sus filas quien encabece esa convergencia nacional que hay que montar para el 2014, pero esa es la idea, siempre en torno a un programa que tiene que con- tener unos elementos básicos con respecto a lo democrático, defensa de la producción nacional, industrial, agropecuaria, incluida la empresarial, defensa del trabajo y todo lo que tiene que ver con la vida del pueblo, salud, educación, salarios, etc., defensa de la democracia, y ahí se incluye el repudio a estas prácticas corruptas que son tan propias de la política nacional y también el rechazo a la lucha armada como manera de resolver los problemas políticos del país. Al mismo tiempo la idea de que lo mejor es que el conflicto armado se resuelva mediante soluciones de tipo político, y por ultimo debe estar también planteado con toda claridad, que Colombia si esta para relacionarse con todos los países del mundo, pero no como un país vasallo, no en una alianza de mula y jinete como la que por ejemplo nos imponen los TLCs.

Los señalo como elementos que tendría que tener ese gran acuerdo que se armara del otro lado, porque si no es un programa de acuerdo para cambiar a Colombia, para que acuerdo. Si es para hacer lo mismo que ellos están haciendo, entonces no tiene sentido que hagamos nada, pero si digamos que ese es el enfoque general, es tratar de promover un gran proyecto que sea capaz de ganar las elecciones en el 2014. 